\title{
Physicians are a key to encouraging cessation of smoking among people living with HIV/AIDS: a cross-sectional study in the Kathmandu Valley, Nepal
}

Rachel M Amiya ${ }^{1}$, Krishna C Poudel ${ }^{1 *}$, Kalpana Poudel-Tandukar ${ }^{2}$, Jun Kobayashi ${ }^{3}$, Basu D Pandey ${ }^{4}$ and Masamine Jimba'

\begin{abstract}
Background: HIV care providers may be optimally positioned to promote smoking behaviour change in their patients, among whom smoking is both highly prevalent and uniquely harmful. Yet research on this front is scant, particularly in the developing country context. Hence, this study describes smoking behaviour among people living with HIV/AIDS (PLWHA) in the Kathmandu Valley of Nepal, and assesses the association between experience of physician-delivered smoking status assessment and readiness to quit among HIV-positive smokers.

Methods: We conducted a cross-sectional survey of PLWHA residing in the Kathmandu Valley, Nepal. Data from 321 adult PLWHA were analyzed using multiple logistic regression for correlates of current smoking and, among current smokers, of motivational readiness to quit based on the transtheoretical model (TTM) of behaviour change.

Results: Overall, $47 \%$ of participants were current smokers, with significantly higher rates among men (72\%), everinjecting drug users (IDUs), recent (30-day) alcohol consumers, those without any formal education, and those with higher HIV symptom burdens. Of 151 current smokers, 34\% were thinking seriously of quitting within the next 6 months (contemplation or preparation stage of behaviour change). Adjusting for potential confounders, experience of physician-delivered smoking status assessment during any visit to a hospital or clinic in the past 12 months was associated with greater readiness to quit smoking ( $A O R=3.34 ; 95 \% \mathrm{Cl}=1.05,10.61$ ).

Conclusions: Roughly one-third of HIV-positive smokers residing in the Kathmandu Valley, Nepal, are at the contemplation or preparation stage of smoking behaviour change, with rates significantly higher among those whose physicians have asked about their smoking status during any clinical interaction over the past year. Systematic screening for smoking by physicians during routine HIV care may help to reduce the heavy burden of smoking and smoking-related morbidity and mortality within HIV-positive populations in Nepal and similar settings.
\end{abstract}

\section{Background}

As expanding global application of antiretroviral therapy (ART) heralds a paradigm shift in HIV-related morbidity and mortality [1-5], the time is ripe to address tobacco smoking as a bottleneck to gains in life expectancy among people living with HIV/AIDS (PLWHA) [6,7]. Recent studies from HIV-positive cohorts in developed

\footnotetext{
* Correspondence: krishna@m.u-tokyo.ac.jp

'Department of Community and Global Health, Graduate School of Medicine, University of Tokyo, Tokyo, Japan

Full list of author information is available at the end of the article
}

country settings indicate that rates of current smoking (41-66\%) [7-10] are two to three times higher than corresponding general population rates, and similarly elevated smoking rates have been observed among PLWHA in developing African countries [11-14]. In addition to accelerating the development of well-known tobaccoassociated morbidities [15], smoking weakens the body's immune and virological response [16], rendering HIVpositive smokers more vulnerable to disease and opportunistic infection and less responsive to ART $[17,18]$. PLWHA who smoke report lower quality of life and face

\section{C) Biomed Central}


significantly elevated risks of non-AIDS cancers, cardiovascular disease, bacterial pneumonia, and all-cause mortality relative to non-smoking PLWHA [8,10,19-21].

Yet even for individuals with protracted tobacco use histories, cessation brings almost immediate health benefits and can, over time, reduce the risk of premature death to a level approaching that of a lifetime non-smoker [22,23]. From an HIV-specific perspective, evidence confirms that quitting smoking can dramatically relieve symptom burden [24] and improve health outcomes, including reduced risk of bacterial pneumonia [25] and cardiovascular disease [26]. Moreover, facilitation of smoking cessation alongside HIV treatment may help prevent medication failures and substance use relapse $[27,28]$.

A key component and predictor of successful outcomes in the process of smoking cessation is motivational readiness to change $[29,30]$, described in the transtheoretical model (TTM) of health behaviour change [31,32]. In the case of smoking, one study suggests that advancement from precontemplation (not thinking of quitting within the next 6 months) to contemplation (thinking of quitting in the next 1-6 months) increases the likelihood of future (2-year) cessation by $40 \%$, and that advancement to preparation (thinking of quitting within the next 30 days, with at least one 24-hour quit attempt in the past year) increases that likelihood by $80 \%$ [30]. Among HIV-positive smokers, several cross-sectional studies carried out in the United States report that $58-64 \%$ of those treated in outpatient clinics are thinking seriously of quitting within the next 6 months [9,33-35], indicating a certain readiness and likelihood to proceed through the remaining stages of change. Understanding what characteristics or inputs might impact readiness to quit among HIV-positive smokers is key to devising effective strategies to promote cessation.

One promising vehicle for reaching HIV-positive smokers may lie in the frequent contact between HIV-positive smokers and their physicians facilitated by the need for regular immunologic monitoring and, for many, ART support. Given this heightened level of interaction and trust [36], HIV medical systems and personnel would seem ideally placed to effect behaviour change in this important population of smokers. Indeed, a previous study carried out among state employees in the United States identified patients' trust in their physician and physicians' knowledge of patients as leading correlates of adherence to physician's advice [37].

Within the general population, even simple interventions delivered by physicians in the form of brief encouragement or advice to quit smoking can have a significant impact on short-term movement through the stages of change [38] and on future quitting rates [39]. However, the effect of such basic interventions remains unclear in the context of HIV care systems, where the space for positive impact may be even greater. If shown effective, the implementation of such basic awareness-raising measures could represent an important first step toward tackling the troubling intersection of HIV and tobacco epidemics, particularly in the hard-hit and resource-limited countries of the developing world.

Despite the exceptional health risks associated with tobacco smoking and the clear benefits of quitting for HIV-positive smokers, attention to smoking behaviour and motivational readiness to quit has been inadequate in this important smoking subgroup. Moreover, although over $90 \%$ of the world's HIV-positive population resides in the developing world [40], data on tobacco use among PLWHA outside of Europe and North America have been limited to several descriptive reports from Africa [11-14].

We therefore explored factors associated with current smoking status and readiness to quit among PLWHA residing in the Kathmandu Valley of Nepal, among the least developed countries in South Asia. In particular, this study examined the association between experience of physician-delivered smoking status assessment and motivational readiness to quit in HIV-positive smokers.

\section{Methods}

\section{Study design and setting}

This cross-sectional study surveyed a community-based sample of $321 \mathrm{HIV}$-positive residents of the Kathmandu Valley, Nepal. Since the country's first case of HIV was reported in 1988, Nepal has been facing a burgeoning concentrated epidemic, with prevalence especially high among injecting drug users (IDUs) [41]. In the capital city of Kathmandu, HIV prevalence among IDUs was 34.8\% in 2007 [42]. The Kathmandu Valley comprises three districts (Kathmandu, Lalitpur, and Bhaktapur) with an estimated population of 2.2 million [43]. Of Nepal's estimated 70,000 adult (15-49 years) PLWHA [41], 15.7\% were residing in the Kathmandu Valley at the end of 2006 [44].

\section{Data collection}

We recruited 322 participants through purposive, convenience sampling techniques. Potential participants were referred through staff members of five local non-governmental organizations (NGOs) working within HIV-positive communities in the Kathmandu Valley. Individuals recruited for participation fulfilled the following inclusion criteria: (1) 16 to 60 years of age, (2) self-reported diagnosis of HIV-positive status, and (3) willing provision of written informed consent for voluntary participation.

Data collection was undertaken during February and March 2010 in the wider context of the baseline phase of a longitudinal healthy living intervention overseen by the second author (KCP). The survey was based on a structured, pre-tested Nepali language questionnaire. Trained interviewers administered the questionnaire face-to-face 
in a private setting, with each interview lasting approximately 45-60 minutes. All participants were informed about the study procedures using a prepared information sheet, and signed informed consent forms prior to being interviewed. To enhance confidentiality, interviewers reassured participants that numerical codes would be used in place of names in all records. The study protocol was reviewed and ethical approval granted by the Institutional Review Board of the Graduate School of Medicine at the University of Tokyo and by the Nepal Health Research Council.

\section{Measures}

Sociodemographic, clinical, and psychosocial characteristics Standard single questionnaire items assessed basic sociodemographic and HIV-specific clinical variables. We used the HIV Symptom Index (HSI) [45], which assesses the presence and degree of 20 symptoms commonly experienced by PLWHA, to measure HIV symptom burden (Cronbach's alpha $=0.89$ ). Participants reported whether each symptom was present, and if so, whether it was bothersome, by using a five-point Likert scale (0-4) ranging from "I do not have this symptom" (0) to "I have it and it bothers me a lot" (4). We dichotomized each item into absent/not bothersome (0-2) vs. present and bothersome (3-4), and summed these scores to obtain a bothersome symptom count [45].

A modified 7-item version of the AIDS-related Stigma Scale [46] was used to assess internalized AIDS stigma (Cronbach's alpha $=0.74$ ). Responses were given dichotomously ( 0 = disagree, 1 = agree); scale scores represent the sum total of endorsed items, with higher scores indicating more negative attitudes or perceived discrimination. Additionally, the 21-item Beck Depression Inventory (BDI), Nepali version $[47,48]$, was used to assess depression in participants (Cronbach's alpha = 0.90).

\section{Smoking-related variables}

Current smoking status was assessed by single items asking participants about smoking frequency at the time of the survey and about amount smoked both daily and cumulatively. Based on definitions set forth by the CDC [49], we classified participants as current smokers if they reported smoking "every day" or "some days" at the time of survey. Participants who had smoked at least 100 cigarettes in their lifetime but had quit smoking at the time of the interview were considered former smokers, while those reporting never smoking or smoking fewer than 100 cigarettes in their lifetime were considered never smokers.

Frequency of smoking as a measure of smoking intensity was assessed by asking current smokers how many cigarettes they smoked in a typical day. Current smokers were then categorized as light smokers ( $\leq 10$ cigarettes/ day) or moderate-to-heavy smokers (> 10 cigarettes/day) [50]. Current smokers were also asked whether they smoked fewer, more, or about the same number of cigarettes since finding out they were HIV-positive [51]. We identified previous quit attempts by asking current smokers whether they had stopped smoking for at least one day during the past 12 months because they were trying to quit smoking. Additional items addressed to current smokers covered age of smoking initiation and cohabitation with other smokers.

\section{Health care provider-delivered smoking status assessment}

Experience of smoking status assessment by a health care provider was measured by first asking all participants their frequency of visits to a hospital or clinic for any reason over the 12 months preceding the time of survey. Those reporting at least one visit to a hospital or clinic during that time $(n=302)$ then responded to three items inquiring whether a physician, paramedic, or nurse had ever asked about their smoking status during any such visit.

\section{Readiness to quit smoking}

Current smokers' readiness to quit smoking was assessed based on the following question: "Are you seriously thinking of quitting smoking?" According to the conventions of the TTM [29], participants reporting no intention to quit within the next 6 months or no intention to quit at all were placed in the pre-contemplation stage, while those reporting an intention to quit in the next 1-6 months were classified as falling within the contemplation stage. Those expressing an intention to quit within the next 30 days and also reporting a previous quit attempt in the past 12 months were categorized in the preparation stage of change.

\section{Statistical analysis}

Of 322 eligible participants, data from one male participant was incomplete and thus excluded from analysis. The remaining 321 HIV-positive individuals (184 males, 137 females) constituted our study sample.

Multiple logistic regression analysis was used to explore factors associated with smoking status and to examine the association between experience of physician-delivered smoking status assessment and readiness to quit smoking, comparing current smokers in lower (pre-contemplators) and higher (contemplators and preparators) stages of change in terms of potential covariates. Independent variables were entered into each regression using a direct (simultaneous) entry method. Major sociodemographic characteristics and other mediators having previously established or theoretically feasible associations with the dependent variables were included as covariates or potential confounders in the analyses. Multicollinearity was also assessed for each model, and the variance inflation factor (VIF) of all variables was less than 3.0. All statistical tests were 2 -sided, considered significant at the $\mathrm{p}<0.05$ level, 
and performed using SPSS version 18.0 for Windows (SPSS Inc., Chicago, IL).

\section{Results}

\section{Background characteristics}

The surveyed group was $57 \%$ male and had a median age of 33 (interquartile range $[\mathrm{IQR}]=30,39$ ) years; $81 \%$ of participants had at least some formal education (Table 1). Median period since testing HIV-positive was 53 (IQR = $25,84)$ months and $73 \%$ of participants were on ART at the time of survey. Median bothersome HIV symptom count was $3(\mathrm{IQR}=1,7)$, and around a quarter $(26 \%)$ of participants registered moderate-to-severe depression. Overall, $41 \%$ of participants had a lifetime history of injecting drug use.

\section{Smoking prevalence and characteristics}

Of the 321 participants, $47 \%$ were current smokers at the time of survey - $72 \%$ of male and $15 \%$ of female participants. Median age of smoking initiation among the 152 current smokers was 14 years (IQR $=12,17$ years), and roughly half $(51 \%)$ were moderate-to-heavy smokers (Table 2). Nearly two-thirds (62\%) of all current smokers reported some change in their level of smoking since testing HIV-positive, with $45 \%$ reporting a reduction and $17 \%$ reporting an increase. A total of 23 participants (19 men, 4 women) had quit smoking subsequent to testing HIVpositive.

Regarding readiness to quit, 51 current smokers (34\%) had reached or surpassed the contemplation stage of change, with some thought of quitting within the next six months. Roughly half (52\%) of current smokers had made at least one quit attempt within the past 12 months; the most commonly cited reason for relapse was "Addiction/ Habit" (45\%), followed by "Boredom" (32\%).

Among the 137 current smokers reporting at least one visit to a hospital or clinic within the past 12 months, 73\% reported experience of physician-delivered smoking status assessment during any such visit. Further, 26\% reported experience of paramedic- or nurse-delivered smoking status assessment within the same parameters.

\section{Factors associated with current smoking}

Men were over nine times more likely than women to be current smokers $(\mathrm{AOR}=9.20 ; 95 \% \mathrm{CI}=3.80,22.26$ ) (Table 3). Additionally, current smoking was nearly six times as prevalent among participants with a lifetime history of injecting drug use (AOR $=5.72 ; 95 \% \mathrm{CI}=2.74$, $11.92)$, over three times as prevalent among those reporting any alcohol consumption in the past 30 days $(\mathrm{AOR}=$ 3.19; $95 \% \mathrm{CI}=1.10,9.30$ ), and twice as prevalent among those with higher HIV symptom burdens $(\mathrm{AOR}=2.06$; $95 \% \mathrm{CI}=1.04,4.10)$. Conversely, participants having any
Table 1 Background characteristics of participants

( $N=321)$

\begin{tabular}{lccc}
\hline Characteristic & $\mathbf{n}^{\mathbf{a}}$ & (\%) \\
\hline & Sociodemographics & & \\
Gender & & & \\
Male & 137 & $(57.3)$ \\
Female & 184 & $(42.7)$ \\
& & & \\
Age (years) & & \\
$20-29$ & 78 & $(34.2)$ \\
$30-39$ & 165 & $(47.0)$ \\
$40-60$ & 76 & $(18.8)$
\end{tabular}

Current marital status

Unmarried

$101 \quad$ (31.5)

Married

Education level $^{b}$

No formal education

Primary (1-5 yrs.)

Lower secondary (6-10 yrs.)

Higher secondary and above (11+ yrs.)

Monthly income $(\mathrm{NRs})^{\mathrm{C}}($ Median $=4000)$

0

200-4000

(28.3)

4001-300000

Any children

No

(31.8)

Yes

Sexual orientation

Heterosexual

(99.4)

Homo- or bi-sexual

Clinical and psychosocial characteristics

Months since first testing HIV+ (Median = 53)

$1-53$

$54+$

Months on ART (Median = 24)

Not currently on ART

(27.2)

$1-24$

$25+$

Experience of TB diagnosis since testing HIV+

No

Yes

Bothersome HIV symptom count (Median = 3)

$0-3$ 
Table 1 Background characteristics of participants ( $\mathbf{N}=321)$ (Continued)

\begin{tabular}{|c|c|c|}
\hline \multicolumn{3}{|l|}{ Smoking status } \\
\hline Never smoker & 129 & $(40.2)$ \\
\hline Former smoker & 40 & $(12.5)$ \\
\hline Current smoker & 152 & $(47.4)$ \\
\hline \multicolumn{3}{|c|}{ Injection drug use history ${ }^{d}$} \\
\hline Never user & 191 & $(60.1)$ \\
\hline Former user & 100 & (31.4) \\
\hline Current user & 27 & $(8.5)$ \\
\hline \multicolumn{3}{|c|}{ Alcohol use, last 30 days } \\
\hline No & 281 & $(87.5)$ \\
\hline Yes & 40 & $(12.5)$ \\
\hline \multicolumn{3}{|c|}{ Marijuana use, last 6 months } \\
\hline No & 290 & $(90.3)$ \\
\hline Yes & 31 & $(9.7)$ \\
\hline \multicolumn{3}{|c|}{ Internalized AIDS stigma score $($ Median $=4)$} \\
\hline $0-4$ & 187 & $(58.3)$ \\
\hline $5-7$ & 134 & $(41.7)$ \\
\hline \multicolumn{3}{|c|}{ Beck Depression Inventory score ${ }^{e}$} \\
\hline$<20$ & 239 & $(74.5)$ \\
\hline $20+$ & 82 & $(25.5)$ \\
\hline \multicolumn{3}{|c|}{ NRs, Nepalese Rupees. ART, antiretroviral therapy. } \\
\hline \multicolumn{3}{|c|}{ a Total sample size varies due to missing data. } \\
\hline \multicolumn{3}{|c|}{${ }^{b}$ Based on the structure of the Nepalese education system. } \\
\hline \multicolumn{3}{|c|}{ c 4000 NRs $=$ US $\$ 55$ approximately, as of February 2010} \\
\hline \multicolumn{3}{|c|}{$\begin{array}{l}\text { d Former users: participants reporting a lifetime history of injecting drug use } \\
\text { but no use in the last } 6 \text { months classified. Current users: participants reporting } \\
\text { injecting drug use in the last } 6 \text { months. Never users: participants reporting no } \\
\text { lifetime history of injecting drug use. Three participants who indicated a } \\
\text { lifetime history of injecting drug use did not respond to the question } \\
\text { regarding 6-month use and hence could not be distinguished as former or } \\
\text { current users. }\end{array}$} \\
\hline \multicolumn{3}{|c|}{$\begin{array}{l}\text { e A score of } 20 \text { or more on the Beck Depression Inventory defined the } \\
\text { presence of moderate-to-severe depressive symptoms, based on clinical } \\
\text { validation of the scale in Nepal (sensitivity }=0.73 \text {, specificity }=0.91 \text { ) [48]. }\end{array}$} \\
\hline
\end{tabular}

level of formal education were nearly three times less likely than those without any formal education to be current smokers $(\mathrm{AOR}=0.35 ; 95 \% \mathrm{CI}=0.14,0.84)$.

\section{Factors associated with readiness to quit smoking}

Experience of physician-delivered smoking status assessment during any visit to a hospital or clinic in the last 12 months was significantly associated with higher readiness to quit among the surveyed HIV-positive smokers $(\mathrm{AOR}=3.34 ; 95 \% \mathrm{CI}=1.05,10.61)($ Table 4$)$. Additionally, current smokers reporting at least one prior quit attempt in the past 12 months were significantly more likely than those reporting no such attempt
Table 2 Tobacco use characteristics of current smokers ( $N=152$ )

\begin{tabular}{|c|c|c|}
\hline Characteristic & $\mathrm{n}^{\mathrm{a}}$ & (\%) \\
\hline \multicolumn{3}{|l|}{ Age of smoking initiation (years) $($ Median $=14)$} \\
\hline $7-14$ & 78 & $(51.7)$ \\
\hline $15+$ & 73 & $(48.3)$ \\
\hline \multicolumn{3}{|l|}{ Average daily smoking intensity, last 30 days } \\
\hline Light smoker ( $\leq 10$ cigarettes/day) & 75 & $(49.3)$ \\
\hline Moderate-to-heavy smoker (> 10 cigarettes/day) & 77 & $(50.7)$ \\
\hline \multicolumn{3}{|l|}{ Presence of other smoker in household } \\
\hline No & 70 & $(46.1)$ \\
\hline Yes & 82 & $(53.9)$ \\
\hline \multicolumn{3}{|l|}{ Change in smoking level since testing HIV+ } \\
\hline Cut down & 68 & $(44.7)$ \\
\hline About the same & 58 & $(38.2)$ \\
\hline Increased & 26 & $(17.1)$ \\
\hline
\end{tabular}

$\begin{array}{lcc}\text { Readiness to quit smoking (Stage of change) } & & \\ \text { Pre-contemplation } & 100 & (66.2) \\ \text { Contemplation } & 26 & (17.2) \\ \text { Preparation } & 25 & (16.6)\end{array}$

Prior quit attempt, last 12 months

\begin{tabular}{lll} 
No & 74 & $(48.7)$ \\
Yes & 78 & $(51.3)$ \\
\hline
\end{tabular}

${ }^{a}$ Total numbers of respondents vary due to missing data.

to be contemplating quitting within the next 6 months $(\mathrm{AOR}=3.77 ; 95 \% \mathrm{CI}=1.48,9.58)$, as were smokers having at least one other regular smoker in the household $(\mathrm{AOR}=2.91 ; 95 \% \mathrm{CI}=1.16,7.29)$. Conversely, having any formal education was significantly associated with being in the precontemplative stage of behaviour change, showing an inverse relationship with readiness to quit $(\mathrm{AOR}=0.12 ; 95 \% \mathrm{CI}=0.02,0.71)$.

\section{Discussion}

This study revealed that HIV-positive smokers reporting experience of physician-delivered smoking status assessment during any visit to a hospital or clinic in the past 12 months were over three times more likely to be in the contemplation or preparation stage of readiness to quit smoking. Outside of gender, lifetime history of injecting drug use showed the most robust association with current smoking status, followed by 30-day alcohol consumption, lack of formal education, and HIV symptom burden. Thus, optimal targeting of high-risk groups for smoking cessation efforts within the HIV-positive community would focus especially on males and recovering or active IDUs, incorporating the physician as a viable conduit for smoking cessation interventions. 
Table 3 Multiple logistic regression analysis of factors associated with current smoking ${ }^{\mathrm{a}}$ among participants $\left(\mathrm{N}=301^{\mathrm{b}}\right)$

\begin{tabular}{|c|c|c|}
\hline Variable & AOR & $(95 \% \mathrm{Cl})$ \\
\hline \multicolumn{3}{|l|}{ Gender } \\
\hline Male & 9.20 & $(3.80,22.26)^{* *}$ \\
\hline Female (Ref) & 1.00 & \\
\hline
\end{tabular}

Age (years)

$34+$

20-33 (Ref)

$0.72(0.36,1.43)$

1.00

Marital status

Married

Unmarried (Ref)

$0.92(0.43,1.96)$

1.00

Any formal education

Yes

No (Ref)

0.35

1.00

Monthly income (NRs) ${ }^{c}$

$4001+$

0-4000 (Ref)

$0.74(0.39,1.40)$

1.00

Any children

Yes

No (Ref)

$1.03(0.49,2.16)$

1.00

Months since first testing HIV+

$54+$

1-53 (Ref)

1.51

1.00

Currently receiving ART

Yes

No (Ref)

0.77

1.00

Bothersome HIV symptom count

4-20

0-3 (Ref)

Experience of TB diagnosis since testing HIV+

Yes

No (Ref)

1.00

Internalized AIDS stigma score

5-7

0-4 (Ref)

Beck Depression Inventory score ${ }^{d}$

20+

$<20$ (Ref)

$0.49(0.22,1.11)$

1.00
Table 3 Multiple logistic regression analysis of factors associated with current smoking ${ }^{a}$ among participants $\left(\mathbf{N}=\mathbf{3 0 1}^{\mathbf{b}}\right.$ ) (Continued)

\begin{tabular}{|c|c|c|}
\hline Yes & 5.72 & $(2.74,11.92)^{* *}$ \\
\hline No (Ref) & 1.00 & \\
\hline \multicolumn{3}{|c|}{ Alcohol consumption, last 30 days } \\
\hline Yes & 3.19 & $(1.10,9.30)^{*}$ \\
\hline No (Ref) & 1.00 & \\
\hline \multicolumn{3}{|c|}{ Marijuana use, last 6 months } \\
\hline Yes & 2.59 & $(0.73,9.15)$ \\
\hline No (Ref) & 1.00 & \\
\hline \multicolumn{3}{|c|}{ Presence of smoker among other household members } \\
\hline Yes & 1.09 & $(0.58,2.02)$ \\
\hline No (Ref) & 1.00 & \\
\hline \multicolumn{3}{|c|}{$\begin{array}{l}A O R \text {, adjusted odds ratio. } C l \text {, confidence interval. } A R T \text {, antiretroviral therapy. } \\
\text { a The reference group was current non-smokers. }\end{array}$} \\
\hline \multicolumn{3}{|c|}{$\begin{array}{l}{ }^{b} \text { After accounting for the collective set of missing values associated with the } \\
\text { variables included in the multivariable model, data from } 301 \text { participants were } \\
\text { analyzed. }\end{array}$} \\
\hline \multicolumn{3}{|c|}{$\begin{array}{l}\text { c } 4000 \text { NRs }=\text { US } \$ 55 \text { approximately, as of February } 2010 . \\
\text { d A score of } 20 \text { or more on the Beck Depression Inventory defined the }\end{array}$} \\
\hline \multicolumn{3}{|c|}{$\begin{array}{l}{ }^{d} \text { A score of } 20 \text { or more on the Beck Depression Inventory defined the } \\
\text { presence of moderate-to-severe depressive symptoms, based on clinical } \\
\text { validation of the scale in Nepal (sensitivity }=0.73 \text {, specificity }=0.91 \text { ) [48]. }\end{array}$} \\
\hline
\end{tabular}

As expected, current smoking was highly prevalent among PLWHA in our study, particularly among male participants. Though our data reveal a current smoking prevalence among HIV-positive women roughly comparable to the national rate for women in the region (16.0\%), the prevalence of smoking among HIV-positive men was over twice the corresponding national rate (34.8\%) [52]. Identified predictors of current smoking status were generally consistent with results of previous studies conducted within HIV-positive populations in Western, developed settings [10,33] and in Africa [11].

In terms of motivational readiness to quit, the proportion of participants still in the precontemplative stage of behaviour change was high relative to previous findings on HIV-positive smokers in developed countries $[9,33,34]$. Velicer et al. [53] reported typical proportions for readiness to quit as $40 \%$ in precontemplation, $40 \%$ in contemplation, and $20 \%$ in preparation among smokers in the general population. In our sample, in contrast, roughly two-thirds of smokers were precontemplative about quitting. This finding underscores the prime importance of exploring effective ways to build motivation for cessation in this important population of smokers.

Our study is the first to report on formal education as a potential barrier to quitting readiness among HIV- 
Table 4 Multiple logistic regression analysis of factors associated with readiness to quit (contemplation or preparation stage of change) $)^{a}$ among current smokers visiting a hospital or clinic in the past 12 months $\left(\mathrm{N}=131^{\mathrm{b}}\right.$ )

\begin{tabular}{lcc}
\hline Variable & AOR & (95\% Cl) \\
\hline Gender & & \\
$\quad$ Male & 5.79 & $(0.86-39.10)$ \\
$\quad$ Female (Ref) & 1.00 &
\end{tabular}

Age (years)

$34+$

20-33 (Ref)

$(0.40-3.03)$

Marital status

Married

Unmarried (Ref)

$(0.39-4.30)$

1.00

Any formal education

Yes

No (Ref)

$0.12(0.02-0.71)^{*}$

Monthly income (NRs)

$4001+$

0-4000 (Ref)

Any children

Yes

No (Ref)

Months since first testing HIV+

$54+$

1-53 (Ref)

Currently receiving ART

Yes

No (Ref)

Bothersome HIV symptom count

$$
\text { 4-20 }
$$

0-3 (Ref)

Experience of TB diagnosis since testing HIV+

$$
\text { Yes }
$$

No (Ref)

Number of hospital visits, last 12 months

$$
3+
$$

1-2 (Ref)

Beck Depression Inventory score $^{\mathrm{d}}$

$$
20+
$$

$<20$ (Ref)
$1.20 \quad(0.41-3.57)$

1.00
Table 4 Multiple logistic regression analysis of factors associated with readiness to quit (contemplation or preparation stage of change) ${ }^{\mathrm{a}}$ among current smokers visiting a hospital or clinic in the past 12 months $\left(N=131^{\text {b }}\right)$ (Continued)

\begin{tabular}{lll}
\hline Lifetime injecting drug use & & \\
Yes & 0.50 & $(0.16-1.60)$ \\
No (Ref) & 1.00 &
\end{tabular}

Presence of smoker among other household members

$\begin{array}{lll}\text { Yes } & 2.91 & (1.16-7.29)^{*} \\ \text { No (Ref) } & 1.00 & \end{array}$

\begin{tabular}{|c|c|}
\hline $\begin{array}{l}\text { Moderate-to-heavy smoker (> } 10 \text { cigarettes/ } \\
\text { day) }\end{array}$ & 0.42 \\
\hline ght smoker ( $\leq 10$ cigarettes/day) (Ref) & \\
\hline
\end{tabular}

Age of smoking initiation (years)

$\begin{array}{lll}15+ & 1.67 & (0.67-4.15) \\ 7-14 \text { (Ref) } & 1.00 & \end{array}$

Average daily smoking intensity, last 30 days

Prior quit attempt, last 12 months

Yes

$3.77(1.48-9.58)$

No (Ref)

Experience of smoking status assessment by a physician, last 12 months

Yes

No (Ref)

Experience of smoking status assessment

by paramedic or nurse, last 12 months

$\begin{array}{lll}\text { Yes } & 1.01 & (0.36-2.85) \\ \text { No (Ref) } & 1.00 & \end{array}$

$A O R$, adjusted odds ratio. $C l$, confidence interval. $A R T$, antiretroviral therapy.

${ }^{a}$ The reference group was current smokers in the precontemplation stage of change.

${ }^{\mathrm{b}}$ After accounting for the collective set of missing values associated with the variables included in the multivariable model, data from 131 participants were analyzed.

c 4000 NRs = US $\$ 55$ approximately, as of February 2010.

${ }^{d}$ A score of 20 or more on the Beck Depression Inventory defined the presence of moderate-to-severe depressive symptoms, according to clinical validation of the scale in Nepal (sensitivity $=0.73$, specificity $=0.91$ ) [48]. ${ }^{*} \mathrm{p}<0.05 ;{ }^{* *} \mathrm{p}<0.01$.

positive smokers. Given the strong positive linear correlation between education and the quit ratio (proportion of ever smokers who had quit smoking) demonstrated by Wetter et al. [54], it may be that those formally educated individuals still smoking at the time of our survey were less likely to be thinking seriously of quitting 
because they had already made a conscious decision to continue smoking, fully cognizant of the attendant risks. Further research would be warranted to elucidate the observed association between education level and readiness to quit smoking among PLWHA and in the developing country context.

Similarly, though data from developed countries suggest that smokers attempting to quit may be less successful and more susceptible to relapse with the presence of another smoker in the household $[55,56]$, our data indicate that cohabitation with at least one other smoker may contribute to greater quitting readiness in some populations. Indeed, social support networks comprise an important aspect of successful smoking cessation [57]. Although this study did not specifically address the readiness to quit of smoking family members, we can reasonably assume that some discussion of quitting is likely to take place where more than one smoker inhabits a household. Future research might fruitfully explore cessation interventions designed to exploit existing support systems through soliciting the involvement of other household smokers.

We further found that history of at least one smoking cessation attempt was associated with greater quitting readiness. This finding is consistent with the TTM, by which the probability of successful change increases with the number of change attempts [32], and is also supported by results from previous studies of HIV-positive smokers [9]. For the promotion of active progression through the stages of change toward cessation, this result recommends the importance of encouraging quit attempts even among those smokers demonstrating lower levels of motivational readiness.

Finally, our research opens up a new and previously unexplored space for the role and effectiveness of basic smoking status screening administered by physicians treating PLWHA. Because the HIV practice pattern typically consists of regular contact over an extended period of time, physicians treating PLWHA have enhanced opportunities to build rapport and trust and to better tailor the tone to the individual patient. Yet there is evidence that HIV care providers may actually be less likely to recognize current smoking in their patients $[51,58]$. This points to a critical missed opportunity.

Notably, we found significantly higher motivational readiness for cessation among individuals reporting smoking status assessment by a physician, though not among individuals reporting such assessment by a paramedic or nurse. This implies that, in the context of this study setting, the words of a physician may be imbued with greater meaning or weight when it comes to issues of health behaviour change. Specifically, paramedics and nurses might be perceived more as peers, as they are frequently available for consultation in the NGO clinics. In contrast, interactions with physicians typically occur in more formal settings, where they may more likely be perceived as expert service providers and their words afforded greater value.

Drawing smokers' attention to their smoking behaviour is a form of feedback to the patient and might in itself be sufficient to effect behaviour change when administered by a trusted and valued health professional. While more intensive, multifaceted counselling interventions may be the ideal, they are not always feasible in busy primary care or clinical settings, particularly in low-resource environments, where health care providers' time is at a premium. From a public health perspective, even given a small effect size for facilitation of smoking cessation through brief physician intervention, the net effect can still be substantial, provided large numbers of physicians follow such a practice systematically [59].

These results should be considered within the context of several study limitations. First, although this study surveyed a large group of participants from multiple NGO outreach networks across the Kathmandu Valley, findings are specifically representative of PLWHA falling within the network of our partner NGOs. Importantly, our sample contained only two non-heterosexual participants, though men who have sex with men represent an important risk group in the HIV epidemic nationally. Second, this study relies on self-report of all measures, leaving room for several types of bias. Because information was collected through face-to-face interviews, a social desirability bias may have been introduced, though a confidential and sensitive method of survey administration was designed to limit this tendency. Although we did not verify smoking status biochemically for those who reported being nonsmokers, there is empirical evidence that selfreport is a sufficient, reliable, and valid means to assess smoking status [60].

Third, measurement of smoking status assessment experiences in this study only covered the existence of such an interaction and did not address potential variability in the specific content or quality of the discussions on smoking taking place between patients and their physicians. Finally, though previous research has established that stage of behaviour change effectively predicts both smoking cessation attempts and actual cessation $[29,30]$, the tangible outcome variable of this study is readiness to quit rather than eventual quitting success. Further research will be needed to gain a better understanding of the different nuances to effective delivery of smoking status assessments in HIV care settings as well as the special needs HIV-positive smokers may have in actually enacting and maintaining smoking cessation.

\section{Conclusions}

Roughly one-third of HIV-positive smokers residing in the Kathmandu Valley, Nepal, are at the contemplation 
or preparation stage of smoking behaviour change, with rates significantly higher among those whose physicians have asked about their smoking status during any clinical interaction over the past year. Although longitudinal studies will be necessary to draw decisive conclusions, our findings suggest an important role for physicians in raising awareness and catalyzing change among their currently smoking HIV-positive patients. Particularly in an era of pervasive ART, the prevention of chronic, tobacco-related disease represents an increasingly critical component of HIV medicine globally. Even through the most minimal investment of time and resources, HIV health care systems show promise as a gateway for effective delivery of smoking cessation interventions to the critical though neglected population of HIV-positive smokers.

\begin{abstract}
Acknowledgements
The authors wish to thank all of the participants for generously sharing with us their time and insights. This work was supported by funding from the University of Tokyo; by the Grant for Research on Global Health and Medicine (No. 21A-2) from the Ministry of Health, Labour, and Welfare; and by the Grant-in-Aid for Young Scientists (B) (22790581) from the Japan Society for the Promotion of Science through the Ministry of Education, Culture, Sports, Science and Technology, Japan. Participants were recruited and collection of data facilitated through five local NGOs working with HIVpositive populations in the Kathmandu Valley, Nepal - Youth Vision, Sneha Samaj, Srijansil Mahila Samuha, SPARSHA Nepal, and Shakti Milan Samaj; we gratefully acknowledge their invaluable support.
\end{abstract}

\section{Author details}

'Department of Community and Global Health, Graduate School of Medicine, University of Tokyo, Tokyo, Japan. ${ }^{2}$ Waseda Institute for Advanced Study, Waseda University, Tokyo, Japan. ${ }^{3}$ Bureau of International Cooperation, National Center for Global Health and Medicine, Tokyo, Japan. ${ }^{4}$ Sukraraj Tropical and Infectious Disease Hospital, Kathmandu, Nepal.

\section{Authors' contributions}

RMA conceived of the study, contributed to the study design, conducted the statistical analyses, and drafted the article. KCP helped to conceptualize the study and contributed to the design of the study, the interpretation of results, and the revisions of the article. RMA, KCP, and KPT oversaw the data collection. JK and BDP assisted in the implementation of the study. MJ monitored and supervised the study progress. All authors contributed to critical revision of and approved the final manuscript.

\section{Competing interests}

The authors declare that they have no competing interests.

Received: 12 July 2011 Accepted: 31 August 2011

Published: 31 August 2011

\section{References}

1. Palella FJ, Baker RK, Moorman AC, Chmiel JS, Wood KC, Brooks JT, Holmberg SD, HIV Outpatient Study Investigators: Mortality in the highly active antiretroviral therapy era: changing causes of death and disease in the HIV outpatient study. J Acquir Immune Defic Syndr 2006, 43(1):27-34.

2. Mocroft A, Ledergerber B, Katlama C, Kirk O, Reiss P, d'Arminio Monforte A, Knysz B, Dietrich M, Phillips AN, Lundgren JD, EuroSIDA study group: Decline in the AIDS and death rates in the EuroSIDA study: an observational study. Lancet 2003, 362(9377):22-29.

3. van Sighem Al, Gras LA, Reiss P, Brinkman K, de Wolf F: Life expectancy of recently diagnosed asymptomatic HIV-infected patients approaches that of uninfected individuals. AIDS 2010, 24(10):1527-1535.
4. Weiss JJ, Osorio G, Ryan E, Marcus SM, Fishbein DA: Prevalence and patient awareness of medical comorbidities in an urban AIDS clinic. AIDS Patient Care STDS 2010, 24(1):39-48.

5. Aldaz $P$, Moreno-Iribas $C$, Egüés N, Irisarri F, Floristan $Y$, Sola-Boneta J, Martínez-Artola V, Sagredo M, Castilla J: Mortality by causes in HIVinfected adults: comparison with the general population. BMC Public Health 2011, 11:300

6. The Data Collection on Adverse Events of Anti-HIV Drugs (D:A:D) Study Group: Factors associated with specific causes of death amongst HIVpositive individuals in the D:A:D Study. AIDS 2010, 24(10):1537-1548.

7. Drach L, Holbert T, Maher J, Fox V, Schubert S, Saddler LC: Integrating smoking cessation into HIV care. AIDS Patient Care STDS 2010, 24(3):139-140.

8. Lifson AR, Neuhaus J, Arribas JR, van den Berg-Wolf M, Labriola AM, Read TR, INSIGHT SMART Study Group: Smoking-related health risks among persons with HIV in the Strategies for Management of Antiretroviral Therapy clinical trial. Am J Public Health 2010, 100(10):1896-1903.

9. Burkhalter JE, Springer CM, Chhabra R, Ostroff JS, Rapkin BD: Tobacco use and readiness to quit smoking in low-income HIV-infected persons. Nicotine Tob Res 2005, 7(4):511-522.

10. Vidrine DJ: Cigarette smoking and HIV/AIDS: health implications, smoker characteristics and cessation strategies. AIDS Educ Prev 2009, 21(3 Suppl):3-13

11. Desalu OO, Oluboyo PO, Olokoba AB, Adekoya AO, Danburam A, Salawu FK, Midala J: Prevalence and determinants of tobacco smoking among HIV patients in North Eastern Nigeria. Afr J Med Med Sci 2009, 38(2):103-108.

12. Jaquet A, Ekouevi DK, Aboubakrine M, Bashi J, Messou E, Maiga M, Traore HA, Zannou M, Guehi C, Ba-Gomis FO, Minga A, Allou G, Eholie SP, Dabis F, Bissagnene E, Sasco AJ: Tobacco use and its determinants in HIVinfected patients on antiretroviral therapy in West African countries. Int J Tuberc Lung Dis 2009, 13(11):1433-1439.

13. Munyati SS, Redzo N, Dauya E, Matambo R, Makamure B, Bandason T, Butterworth AE, Gwanzura L, Rusakaniko S, Mason PR, Corbett EL: Human immunodeficiency virus, smoking and self-rated health in Harare, Zimbabwe. Int J Tuberc Lung Dis 2006, 10(11):1279-1285.

14. Shapiro AE, Tshabangu N, Golub JE, Martinson NA: Intention to quit smoking among human immunodeficiency virus infected adults in Johannesburg, South Africa. Int J Tuberc Lung Dis 2011, 15(1):140-142.

15. US Department of Health and Human Services: The health consequences of smoking: a report of the Surgeon General. Washington, DC: U.S. Government Printing Office; 2004.

16. Kalra R, Singh SP, Savage SM, Finch GL, Sopori ML: Effects of cigarette smoke on immune response: chronic exposure to cigarette smoke impairs antigen-mediated signaling in T cells and depletes IP3-sensitive $\mathrm{Ca}(2+)$ stores. J Pharmacol Exp Ther 2000, 293(1):166-171.

17. Miguez-Burbano MJ, Burbano X, Ashkin D, Pitchenik A, Allan R, Pineda L, Rodriguez N, Shor-Posner G: Impact of tobacco use on the development of opportunistic respiratory infections in HIV seropositive patients on antiretroviral therapy. Addict Biol 2003, 8(1):39-43.

18. Feldman JG, Minkoff H, Schneider MF, Gange SJ, Cohen M, Watts DH, Gandhi M, Mocharnuk RS, Anastos K: Association of cigarette smoking with HIV prognosis among women in the HAART era: a report from the women's interagency HIV study. Am J Public Health 2006, 96(6):1060-1065.

19. Cockerham L, Scherzer R, Zolopa A, Rimland D, Lewis CE, Bacchetti P, Grunfeld C, Shlipak M, Tien PC: Association of HIV infection, demographic and cardiovascular risk factors with all-cause mortality in the recent HAART era. J Acquir Immune Defic Syndr 2010, 53(1):102-106.

20. Crothers K, Griffith TA, McGinnis KA, Rodriguez-Barradas MC, Leaf DA, Weissman S, Gibert CL, Butt AA, Justice AC: The impact of cigarette smoking on mortality, quality of life, and comorbid illness among HIVpositive veterans. J Gen Intern Med 2005, 20(12):1142-1145.

21. Pines H, Koutsky L, Buskin S: Cigarette smoking and mortality among HIVinfected individuals in Seattle, Washington (1996-2008). AIDS Behav 2011, 15(1):243-251.

22. Novello AC: Surgeon General's report on the health benefits of smoking cessation. Public Health Rep 1990, 105(6):545-548.

23. Doll R, Peto R, Boreham J, Sutherland I: Mortality in relation to smoking: 50 years' observations on male British doctors. BMJ 2004, 328(7455):1519.

24. Vidrine DJ, Arduino RC, Gritz ER: The effects of smoking abstinence on symptom burden and quality of life among persons living with HIV/ AIDS. AIDS Patient Care STDS 2007, 21(9):659-666. 
25. Bénard A, Mercié P, Alioum A, Bonnet F, Lazaro E, Dupon M, Neau D, Dabis F, Chêne G, Groupe d'Epidémiologie Clinique du Sida en Aquitaine: Bacterial pneumonia among HIV-infected patients: decreased risk after tobacco smoking cessation. ANRS CO3 Aquitaine Cohort, 2000-2007. PLoS One 2010, 5(1):e8896.

26. Petoumenos K, Worm S, Reiss P, de Wit S, d'Arminio Monforte A, Sabin C, Friis-Møller N, Weber R, Mercie P, Pradier C, El-Sadr W, Kirk O, Lundgren J, Law M, D:A:D Study Group: Rates of cardiovascular disease following smoking cessation in patients with HIV infection: results from the D:A:D study $\left({ }^{*}\right)$. HIV Med 2011

27. Shuter J, Bernstein SL: Cigarette smoking is an independent predictor of nonadherence in HIV-infected individuals receiving highly active antiretroviral therapy. Nicotine Tob Res 2008, 10(4):731-736.

28. Prochaska JJ, Delucchi K, Hall SM: A meta-analysis of smoking cessation interventions with individuals in substance abuse treatment or recovery. J Consult Clin Psychol 2004, 72(6):1144-1156.

29. DiClemente CC, Prochaska JO, Fairhurst SK, Velicer WF, Velasquez MM, Rossi JS: The process of smoking cessation: an analysis of precontemplation, contemplation, and preparation stages of change. $J$ Consult Clin Psychol 1991, 59(2):295-304.

30. Abrams DB, Herzog TA, Emmons KM, Linnan L: Stages of change versus addiction: a replication and extension. Nicotine Tob Res 2000, 2(3):223-229.

31. Prochaska JO, DiClemente CC: Stages and processes of self-change of smoking: toward an integrative model of change. J Consult Clin Psychol 1983, 51(3):390-395.

32. Prochaska JO, Velicer WF: The transtheoretical model of health behavior change. Am J Health Promot 1997, 12(1):38-48.

33. Gritz ER, Vidrine DJ, Lazev AB, Amick BC, Arduino RC: Smoking behavior in a low-income multiethnic HIV/AIDS population. Nicotine Tob Res 2004 6(1):71-77.

34. Mamary EM, Bahrs D, Martinez S: Cigarette smoking and the desire to quit among individuals living with HIV. AIDS Patient Care STDS 2002, 16(1):39-42.

35. Fuster M, Estrada V, Fernandez-Pinilla MC, Fuentes-Ferrer ME, Tellez MJ, Vergas J, Serrano-Villar S, Fernandez-Cruz A: Smoking cessation in HIV patients: rate of success and associated factors. HIV Med 2009, 10(10):614-619.

36. Cunningham CO, Sohler NL, Korin L, Gao W, Anastos K: HIV status, trust in health care providers, and distrust in the health care system among Bronx women. AIDS Care 2007, 19(2):226-234.

37. Safran DG, Taira DA, Rogers WH, Kosinski M, Ware JE, Tarlov AR: Linking primary care performance to outcomes of care. J Fam Pract 1998, 47(3):213-220.

38. Goldberg DN, Hoffman AM, Farinha MF, Marder DC, Tinson-Mitchem L, Burton D, Smith EG: Physician delivery of smoking-cessation advice based on the stages-of-change model. Am J Prev Med 1994, 10(5):267-274.

39. Stead LF, Bergson G, Lancaster T: Physician advice for smoking cessation. Cochrane Database Syst Rev 2008, , 2: CD000165.

40. UNAIDS: 2008 Report on the Global AIDS Epidemic. Geneva: UNAIDS; 2008.

41. Ministry of Health and Population: UNGASS Country Progress Report Nepal. Kathmandu: Ministry of Health and Population, Government of Nepal; 2010.

42. Family Health International, New ERA, STD/AIDS Counselling and Training Services: Integrated Biological and Behavioral Surveillance Survey (IBBS) among Male Injecting Drug Users (IDUs) in Kathmandu Valley, Round IV. Kathmandu: Family Health International; 2009.

43. Central Bureau of Statistics: Statistical Year Book of Nepal - 2009. Kathmandu: National Planning Commission Secretariat, Government of Nepal; 2009.

44. National Centre for AIDS and STD Control: National estimates of HIV infections, Nepal. Kathmandu: National Centre for AIDS and STD Control; 2007.

45. Justice AC, Holmes W, Gifford AL, Rabeneck L, Zackin R, Sinclair G, Weissman S, Neidig J, Marcus C, Chesney M, Cohn SE, Wu AW, Adult AIDS Clinical Trials Unit Outcomes Committee: Development and validation of a self-completed HIV symptom index. J Clin Epidemiol 2001, 54(Suppl 1): S77-90.

46. Simbayi LC, Kalichman S, Strebel A, Cloete A, Henda N, Mqeketo A: Internalized stigma, discrimination, and depression among men and women living with HIV/AIDS in Cape Town, South Africa. Soc Sci Med 2007, 64(9):1823-1831.

47. Kohrt BA, Kunz RD, Koirala NR, Sharma VD, Nepal MK: Validation of a Nepali version of the Beck Depression Inventory. Nep J Psychiatry 2002, 2:123-130.

48. Kohrt BA, Speckman RA, Kunz RD, Baldwin JL, Upadhaya N, Acharya NR, Sharma VD, Nepal MK, Worthman CM: Culture in psychiatric epidemiology: using ethnography and multiple mediator models to assess the relationship of caste with depression and anxiety in Nepal. Ann Hum Biol 2009, 36(3):261-280.

49. Centers for Disease Control and Prevention: Glosssary, NHIS-Adult Tobacco Use Information.[http://www.cdc.gov/nchs/nhis/tobacco/tobacco_glossary. htm], Accessed August 25, 2011.

50. Boulos DN, Loffredo CA, El Setouhy M, Abdel-Aziz F, Israel E, Mohamed MK: Nondaily, light daily, and moderate-to-heavy cigarette smokers in a rural area of Egypt: a population-based survey. Nicotine Tob Res 2009, 11(2):134-138.

51. Tesoriero JM, Gieryic SM, Carrascal A, Lavigne HE: Smoking among HIV positive New Yorkers: prevalence, frequency, and opportunities for cessation. AIDS Behav 2010, 14(4):824-835.

52. Ministry of Health and Population: Nepal Demographic and Health Survey. Kathmandu: Population Division, Ministry of Health and Population, Government of Nepal; 2006.

53. Velicer WF, Fava JL, Prochaska JO, Abrams DB, Emmons KM, Pierce JP: Distribution of smokers by stage in three representative samples. Prev Med 1995, 24(4):401-411.

54. Wetter DW, Cofta-Gunn L, Fouladi RT, Irvin JE, Daza P, Mazas C, Wright K, Cinciripini PM, Gritz ER: Understanding the associations among education, employment characteristics, and smoking. Addict Behav 2005, 30(5):905-914

55. Senore C, Battista RN, Shapiro SH, Segnan N, Ponti A, Rosso S, Aimar D: Predictors of smoking cessation following physicians' counseling. Prev Med 1998, 27(3):412-421.

56. Matheny KB, Weatherman KE: Predictors of smoking cessation and maintenance. J Clin Psychol 1998, 54(2):223-235.

57. Westmaas JL, Bontemps-Jones J, Bauer JE: Social support in smoking cessation: reconciling theory and evidence. Nicotine Tob Res 2010, 12(7):695-707

58. Crothers K, Goulet JL, Rodriguez-Barradas MC, Gibert CL, Butt AA, Braithwaite RS, Peck R, Justice AC: Decreased awareness of current smoking among health care providers of HIV-positive compared to HIVnegative veterans. J Gen Intern Med 2007, 22(6):749-754.

59. Chapman S: The role of doctors in promoting smoking cessation. BMJ 1993, 307(6903):518-519.

60. Patrick DL, Cheadle A, Thompson DC, Diehr P, Koepsell T, Kinne S: The validity of self-reported smoking: a review and meta-analysis. Am J Public Health 1994, 84(7):1086-1093.

\section{Pre-publication history}

The pre-publication history for this paper can be accessed here: http://www.biomedcentral.com/1471-2458/11/677/prepub

doi:10.1186/1471-2458-11-677

Cite this article as: Amiya et al:: Physicians are a key to encouraging cessation of smoking among people living with HIV/AIDS: a crosssectional study in the Kathmandu Valley, Nepal. BMC Public Health 2011 11:677. 